\title{
BMJ
}

\section{Effect of a barrier at Bloor Street Viaduct on suicide rates in Toronto: natural experiment}

\author{
Mark Sinyor, resident physician,, ${ }^{1,2}$ Anthony J Levitt, psychiatrist in chief ${ }^{2}$
}

\begin{abstract}
${ }^{1}$ Department of Psychiatry, University of Toronto, ON, Canada

${ }^{2}$ Department of Psychiatry, Sunnybrook Health Sciences Centre and Women's College Hospital. 2075 Bayview Avenue, Toronto, ON, Canada M4N 3M5

Correspondence to: $\mathrm{M}$ Sinyor
\end{abstract} mark.sinyor@utoronto.ca

Cite this as: BMJ 2010;341:c2884 doi:10.1136/bmj.c2884

\author{
ABSTRACT \\ Objective To determine whether rates of suicide changed \\ in Toronto after a barrier was erected at Bloor Street \\ Viaduct, the bridge with the world's second highest \\ annual rate of suicide by jumping after Golden Gate \\ Bridge in San Francisco. \\ Design Natural experiment.
}

Setting City of Toronto and province of Ontario, Canada; records at the chief coroner's office of Ontario 1993-2001 (nine years before the barrier) and July 2003-June 2007 (four years after the barrier).

Participants 14789 people who completed suicide in the city of Toronto and in Ontario.

Main outcome measure Changes in yearly rates of suicide by jumping at Bloor Street Viaduct, other bridges, and buildings, and by other means.

Results Yearly rates of suicide by jumping in Toronto remained unchanged between the periods before and after the construction of a barrier at Bloor Street Viaduct ( $56.4 \vee 56.6, \mathrm{P}=0.95$ ). A mean of 9.3 suicides occurred annually at Bloor Street Viaduct before the barrier and none after the barrier ( $<$ <0.01). Yearly rates of suicide by jumping from other bridges and buildings were higher in the period after the barrier although only significant for other bridges (other bridges: $8.7 \vee 14.2, \mathrm{P}=0.01$; buildings: 38.5 v 42.7, $\mathrm{P}=0.32$ ).

Conclusions Although the barrier prevented suicides at Bloor Street Viaduct, the rate of suicide by jumping in Toronto remained unchanged. This lack of change might have been due to a reciprocal increase in suicides from other bridges and buildings. This finding suggests that Bloor Street Viaduct may not have been a uniquely attractive location for suicide and that barriers on bridges may not alter absolute rates of suicide by jumping when comparable bridges are nearby.

\section{INTRODUCTION}

It is well recognised that restricting access to a means of suicide may delay or even prevent suicide among vulnerable people. ${ }^{1}$ This principle has been shown successfully in the United Kingdom with the implementation of relatively simple strategies such as switching to carbon monoxide-free sources of gas, ${ }^{2}$ restricting pack sizes of paracetamol (acetaminophen) and salicylates, $^{34}$ and fitting cars with catalytic converters. ${ }^{5}$ In both Canada and New Zealand firearm related suicides decreased after the introduction of legislation for gun control, ${ }^{67}$ although some evidence suggests that these reductions were matched by increases in suicides by other means, such as jumping. ${ }^{89}$

Barriers to prevent jumping have been established at the Empire State Building, the Eiffel Tower, and several bridges worldwide. ${ }^{1011}$ Recent arguments in favour of barriers on bridges used for suicide stem from studies in the 1970s that assessed the survivors of suicide attempts at Golden Gate Bridge in San Francisco, the bridge with the world's highest annual rate of suicide by jumping. ${ }^{10}$ In one study, four of six survivors said that they would not have attempted suicide at any location other than Golden Gate Bridge and all six favoured the construction of a barrier at the bridge. ${ }^{12}$ In another study, only $6 \%$ of 515 people who had been prevented from jumping off Golden Gate Bridge had subsequently completed suicide. ${ }^{13}$ Despite this evidence, $74 \%$ of respondents to a US telephone survey believed that most or all people prevented from jumping off Golden Gate Bridge by a barrier would find another way to complete suicide. ${ }^{14}$ Studies examining the introduction of suicide barriers at Memorial Bridge in Augusta, Maine ${ }^{15}$ and Clifton Suspension Bridge in Bristol, England ${ }^{16}$ as well as the introduction of a safety net at Muenster Terrace in Bern, Switzerland ${ }^{17}$ showed reductions in mean numbers of suicides of $0.6,4.2$, and 2.5 persons per year respectively at each location. Each article examined the change in rates of suicides by jumping from nearby bridges or buildings and concluded that little, if any, substitution of location occurred. However, these studies lacked statistical power because of the relatively small yearly decreases in numbers of suicides at each bridge as well as low rates of suicide in general. No study of a suicide prevention barrier has shown a statistically significant drop in overall rates of suicide in the vicinity.

For more than a decade it has been debated whether a barrier at Bloor Street Viaduct would be effective at preventing suicides in Toronto, Canada. Since the construction of the viaduct in downtown Toronto in 1918, at least 400 people have jumped to their deaths from the bridge. ${ }^{18}$ The $40 \mathrm{~m}$ high viaduct spans two major roads, is $490 \mathrm{~m}$ long, is double decked, and has an arched design with five lanes of traffic above a subway. ${ }^{19}$ With about 10 suicides annually from 1993 
to 2002 (baseline data from this study), Bloor Street Viaduct had the dubious distinction of being the second most popular bridge for suicide studied in the world after Golden Gate Bridge. ${ }^{10}$ The barrier at Bloor Street Viaduct, named the "luminous veil," was constructed between April 2002 and June 2003. The barrier is about $5 \mathrm{~m}$ high and consists of thousands of thin steel rods spaced closely together and supported externally by an angled steel frame. ${ }^{20}$ It is not known whether the barrier has had any impact on Toronto's overall rate of suicides and on the rate of suicides by jumping. We examined coroner's data before and after the construction of the barrier, to determine if suicide rates had changed and whether or not people substituted Bloor Street Viaduct for different locations or means of suicide.

\section{METHODS}

We examined records at the chief coroner's office of Ontario covering all suicides in Ontario from 1 January 1993 to 30 June 2007 . To be included in the data collection the death had to be ruled a suicide by the coroner's office according to the standard of a high degree of probability. Given the large number of charts, it was not possible to examine deaths classified under different categories such as accident, homicide, or undetermined cause of death. Staff at the coroner's office provided a spreadsheet listing all the cases coded as suicides in Ontario for each year in the study. As it takes about two years for a case to be closed, complete data for 2007 were available only in 2009. The following information was included in the spreadsheet: date of suicide, age, sex, region, municipality, and cause of death, such as a fall or jump from a height, hanging, or shooting. We grouped the suicides into four categories: all suicides in Ontario (excluding Toronto), all suicides in Toronto, suicides in Toronto by jumping (where jumping implied from a height, therefore people who jumped in subways were excluded), and suicides in Toronto by means other than jumping. To determine whether the suicide was associated with a bridge or building we examined the charts for all suicides in Toronto coded as a fall or jump from a height. We also obtained the name and location of the bridge associated with the suicide.

The barrier at Bloor Street Viaduct was under construction from April 2002 to June 2003 (correspondence between chief coroner's office and Mike Laidlaw, one of the engineers of the barrier). Accordingly we classified the nine years from 1993 to 2001 as being before the barrier and the four years from 1 July 2003 to 30 June 2007 as being after the barrier. To determine if those who jumped resided in Toronto or had travelled from outside the city, we obtained the postal codes of home residences for 1999-2001 and for 1 July 2003 to 30 June 2007.

The population of Ontario and Toronto was obtained from census data held by Statistics Canada for the years 1996, 2001, and 2006. ${ }^{21}$ We used these data to correct suicide rates for population over time. Linear population growth was assumed for the periods
1996-2001 and 2001-6. We estimated population growth by extrapolating backwards from 1993-6 and forwards from 2006 to June 2007.

\section{Statistical analysis}

To examine differences between suicide rates before and after the barrier we carried out Poisson regression analyses. We analysed demographic data using two tailed, independent sample $t$ tests for continuous variables and two sided $\chi^{2}$ tests for categorical variables. Data on postal codes were analysed using a one sided $\chi^{2}$ test under the assumption that more people would travel from outside the city to complete suicide at Bloor Street Viaduct (before the barrier) than at other bridges in the period after the barrier. We considered a $\mathrm{P}$ value less than 0.05 to be statistically significant.

\section{RESULTS}

Annual rates of suicide by jumping in Toronto remained unchanged before and after the construction of the barrier at Bloor Street Viaduct (56.4 v 56.6, $\mathrm{P}=0.95$; table 1 , fig 1 ). A mean of 9.3 suicides took place annually before the barrier and none after the barrier $(\mathrm{P}<0.01$; fig 2$)$. After the barrier the annual rate of suicides by jumping from bridges other than Bloor Street Viaduct increased significantly (8.7 v. $14.2, \mathrm{P}=0.01)$ and from buildings increased non-significantly (38.5 v 42.7, $\mathrm{P}=0.32$ ). In 2002, the year when construction of the barrier commenced (but was not complete), 63 suicides by jumping occurred in Toronto of which 30 were from bridges and 19 from the Bloor Street Viaduct.

Both the overall rate of suicides in Toronto and the rate of suicides by means other than jumping decreased by 28 suicides per year in the period after the barrier (all Toronto suicides per year: $253.4 v 225.4, \mathrm{P}=0.05$; Toronto suicides per year by other means: $197.0 \mathrm{v} 168.8$, $\mathrm{P}=0.04)$. The decrease in overall rate of suicide in Toronto bordered on statistical significance whereas the decrease in the rate of suicides by other means was significant. The overall annual rate of suicides in Ontario (excluding Toronto) also decreased significantly in the period after the barrier (836.4 v 752.5, $\mathrm{P}=0.01)$.

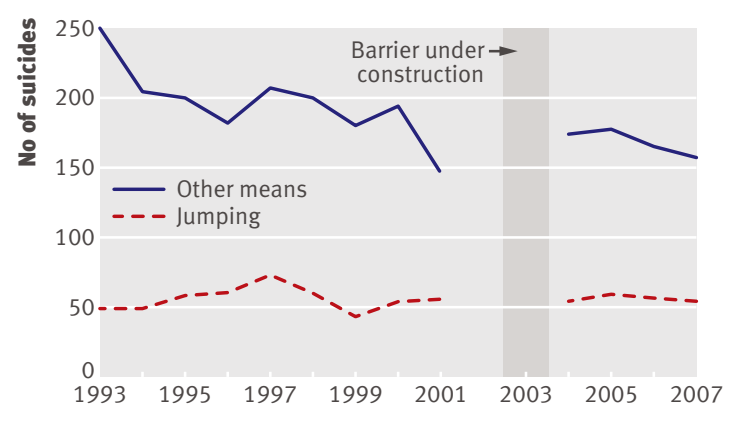

Year

Fig 1 | Suicides in Toronto by jumping or other means before (1993-2001) and after (July 2003-June 2007) construction of a suicide prevention barrier at Bloor Street Viaduct: corrected per capita to suicides in 1993 population (not standardised for age) 
Table 1|Poisson regression analysis of annual suicide rates by jumping and other means in Ontario and Toronto before (1993-2001) and after (July 2003June 2007) construction of a suicide prevention barrier at Bloor Street Viaduct, Toronto

\begin{tabular}{|c|c|c|c|c|c|c|c|c|}
\hline \multirow[b]{2}{*}{ Subgroup } & \multicolumn{2}{|c|}{$\begin{array}{l}\text { Mean No of annual } \\
\text { suicides pre-barrier }\end{array}$} & \multicolumn{2}{|c|}{$\begin{array}{l}\text { Mean No of annual } \\
\text { suicides post-barrier }\end{array}$} & \multirow{2}{*}{$\begin{array}{l}\text { Regression } \\
\text { coefficient }\end{array}$} & \multirow[b]{2}{*}{ Standard error } & \multirow[b]{2}{*}{$P$ value } & \multirow{2}{*}{$\begin{array}{c}\text { Incidence rate ratic } \\
(95 \% \mathrm{Cl}) \dagger\end{array}$} \\
\hline & Observed & Corrected* & Observed & Corrected* & & & & \\
\hline Ontario (excluding Toronto) & 880.1 & 836.4 & 887.5 & 752.5 & -0.11 & 0.04 & 0.01 & 0.90 (0.83 to 0.98$)$ \\
\hline Toronto (total) & 261.2 & 253.4 & 241.8 & 225.4 & -0.12 & 0.06 & 0.05 & $0.89(0.79$ to 1.00$)$ \\
\hline \multicolumn{9}{|l|}{ Suicide method } \\
\hline Jumping & 58.2 & 56.4 & 60.8 & 56.6 & 0.00 & 0.08 & 0.95 & $1.00(0.87$ to 1.17$)$ \\
\hline \multicolumn{9}{|l|}{ Location of jump: } \\
\hline Building & 39.7 & 38.5 & 45.8 & 42.7 & 0.10 & 0.10 & 0.32 & $1.11(0.90$ to 1.36$)$ \\
\hline Bridge & 18.6 & 17.9 & 15.3 & 14.2 & -0.23 & 0.19 & 0.22 & $0.79(0.55$ to 1.15$)$ \\
\hline Bloor Street Viaduct & 9.6 & 9.3 & 0 & 0 & -2.92 & 0.89 & $<0.01$ & $0.05(0.01$ to 0.31$)$ \\
\hline Other bridges & 9.0 & 8.7 & 15.3 & 14.2 & 0.49 & 0.19 & 0.01 & 1.64 (1.13 to 2.39$)$ \\
\hline Other means & 203.0 & 197.0 & 180.8 & 168.8 & -0.15 & 0.08 & 0.04 & $0.86(0.74$ to 0.99$)$ \\
\hline
\end{tabular}

\section{Demographics}

People in Toronto who used means other than jumping to complete suicide after the barrier were older than those who completed suicide by other means before the barrier (48.0 years $v 45.8$ years, $\mathrm{P}<0.01$; table 2 ). Overall in Toronto no other statistically significant differences in age or sex were evident between the periods before and after the barrier. People who completed suicide by jumping in Toronto tended to be younger than those who did so by other means both before and after the barrier. Furthermore, among people who completed suicide by jumping, those who used bridges tended to be younger and were more predominantly male than those who used buildings.

Of the 57 people who completed suicide by jumping from Toronto bridges from 1999-2001 (before the barrier), only two were known to live outside the city and both jumped at Bloor Street Viaduct (table 3). Of the 61 people who completed suicide by jumping from Toronto bridges from July 2003 to June 2007 (after the barrier), nine lived outside the city. More people travelled from outside the city to jump from bridges after the barrier than before the barrier $(\mathrm{P}=0.049)$.

\section{DISCUSSION}

The "luminous veil" was constructed at Bloor Street Viaduct in Toronto to prevent suicides. To be fully successful, it needed to prevent suicides at Bloor Street Viaduct with no reciprocal increases in suicides by jumping at other locations or by other means. The barrier did accomplish the first part of this goal with no suicides occurring at Bloor Street Viaduct during the study period July 2003-June 2007, after the barrier's construction. Something about the barrier's architectural design, its aesthetic quality, or the publicity surrounding its construction was sufficient to dissuade people from considering suicide at that location. This result is in keeping with previous work showing that barriers help to prevent suicides at the location where they are placed. ${ }^{15-182223}$ The overall rate of suicide in Ontario decreased significantly in the period after the barrier's construction. A similar trend was observed in
Toronto, with a decrease in the overall suicide rate that bordered on significance. This decrease in Toronto's overall suicide rate by 28 /year was accompanied by a statistically significant decrease in the same number of suicides per year by means other than jumping. No reduction occurred in the annual suicide rate by jumping in Toronto. Indeed, annual suicides from other bridges in Toronto showed a statistically significant increase, by 5.5 after the barrier (a $63 \%$ increase from the annual rate of 8.7 before the barrier). When this figure is compared with the 9.3 fewer annual suicides at Bloor Street Viaduct after the barrier, it might be speculated that most people who would have jumped at Bloor Street Viaduct chose other bridges instead. Increases in suicides by jumping from buildings may account for the remainder, although these increases did not reach statistical significance, perhaps because of the small numbers involved.

There are several possible explanations for why rates of suicide by jumping did not decrease in Toronto after the barrier was erected. One is that suicide barriers on bridges are not effective in decreasing overall suicide rates because people may substitute a bridge with a barrier for a different location, such as another

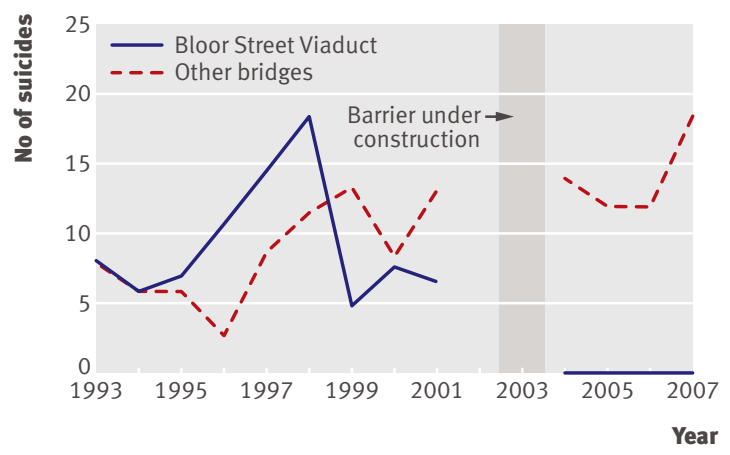

Fig 2 | Suicides in Toronto by jumping from Bloor Street Viaduct and other bridges before (1993-2001) and after (July 2003-June 2007) construction of a suicide prevention barrier at Bloor Street Viaduct: corrected per capita to suicides in 1993 population (not standardised for age) 
bridge or a building. No study of a suicide barrier has shown a statistically significant drop in overall suicide rates in the vicinity. The removal of a suicide barrier on Grafton Bridge in Auckland, New Zealand was associated with a significant increase in suicides. ${ }^{22} \mathrm{How}$ ever, suicides by jumping from other locations decreased by the same number, resulting in an unchanged total rate of suicide by jumping. ${ }^{22}$ That barriers on bridges would be effective was suggested by studies carried out in San Francisco; however, these studies were of people who had either jumped from Golden Gate Bridge and survived ${ }^{12}$ or contemplated suicide or made a suicidal gesture at the bridge that came to the attention of the police or were brought to a hospital. ${ }^{13}$ These two groups may be qualitatively different from people who have been prevented from jumping at a location as a result of a physical barrier. Although some have argued that barriers on bridges are effective at preventing suicide,${ }^{24}$ the evidence in the literature in favour of such barriers when there are other available buildings or bridges is weak, in part due to the scarcity of bridges with pre-barrier suicide rates of sufficient magnitude to make statistical calculations plausible.

A second explanation for the effect observed here is that barriers decrease rates in some instances but that in Toronto specific circumstances led to the barrier failing to decrease overall suicide rates by jumping. The argument for putting a barrier on a notorious suicide bridge as a prevention tool is based on the assumption that people contemplating suicide have a preference for that bridge over others in the area. "Suicide magnet" may be a particularly apt term and has been used to describe suicide bridges in the sense that magnets have the ability to exert different amounts of pull and, presumably, the more pull a magnet exerts the less interchangeable it is with other locations. The evidence presented here shows that despite being the second most frequently used bridge for suicide, Bloor Street Viaduct was a relatively weak magnet. Factors that might make a bridge a stronger "magnet" are ease of pedestrian access, perceived lethality of a jump, and unique geographical features such as being over water.
Bloor Street Viaduct is easily accessed, jumps are highly lethal, and it is constructed over two major roads. However, numerous other bridges in Toronto fit this description. Other considerations are the bridge's aesthetic quality and that of the surrounding environment. Although Bloor Street Viaduct might have been viewed as an impressive structure when it was completed in 1918, it is not aesthetically grand by 21 st century standards and nearby bridges are of similar scale and afford a similar view. A final consideration is the notoriety of the bridge. Although Bloor Street Viaduct is sufficiently notorious to have become a minor pop culture reference, notably in a song by the Barenaked Ladies ${ }^{25}$ and a novel by Michael Ondaatje, ${ }^{26}$ it is not a cultural icon like Golden Gate Bridge. Images and news about Bloor Street Viaduct are not ubiquitous in Toronto compared with Golden Gate Bridge. A survivor of a suicide attempt in San Francisco noted that for him "it was the Golden Gate Bridge or nothing," "12 but whether anyone would make such a bold statement about Bloor Street Viaduct is debatable. One indicator of whether a bridge might hold a degree of importance for people contemplating suicide is if they choose to travel large distances to jump at that location. For example, when Gateway Bridge was opened in Brisbane, Australia, it became a "suicide magnet" after a well publicised suicide at the bridge's opening ceremony. Notably, 100\% of people who died by jumping at that location had travelled there from outside the city compared with only $38 \%$ of people who jumped from a nearby bridge. ${ }^{27}$ This pattern was not, however, observed with Bloor Street Viaduct. Indeed, postal code data show that significantly more people travelled from outside the city to jump from other bridges in the period after the barrier than to jump from Bloor Street Viaduct in the period before the barrier $(\mathrm{P}=0.049)$.

A third explanation is that the barrier at Bloor Street Viaduct could have decreased rates of suicide by jumping under different circumstances. It is important to note that the barrier was a standalone intervention. It has been argued that optimal suicide prevention programmes involve comprehensive strategies to provide

Table 2 | Demographic characteristics of people who completed suicide by jumping or other means in Toronto before (19932001) and after (July 2003-June 2007) the construction of a barrier at Bloor Street Viaduct

\begin{tabular}{|c|c|c|c|c|c|}
\hline \multirow[b]{2}{*}{ Characteristics } & \multicolumn{3}{|c|}{ Location of suicides by jumping } & \multirow[b]{2}{*}{$\begin{array}{l}\text { Suicide by means other } \\
\text { than jumping: } D\end{array}$} & \multirow[b]{2}{*}{$\begin{array}{l}\text { Statistical } \\
\text { comparison* }\end{array}$} \\
\hline & Building : A & $\begin{array}{l}\text { Bloor Street } \\
\text { Viaduct: B }\end{array}$ & Other bridges: $\mathrm{C}$ & & \\
\hline \multicolumn{6}{|l|}{ Mean (SD) age (years): } \\
\hline Before barrier & $43.5(18)$ & $38.1(12.5)$ & $38.6(15.6)$ & $45.8(17.4)$ & $D>A>B=C$ \\
\hline After barrier & $45.8(17.8)$ & - & $38.5(13.6)$ & $48.0(17.2)$ & $D=A>C$ \\
\hline Before versus after barrier* & NS & - & NS & Significant & - \\
\hline \multicolumn{6}{|l|}{ No $(\%)$ of males: } \\
\hline Before barrier & $357(59.4)$ & $86(79.3)$ & $81(78.5)$ & $1827(70.7)$ & $B=C>D>A$ \\
\hline After barrier & $183(64.5)$ & - & $61(72.1)$ & $723(70.1)$ & $C=D=A$ \\
\hline Before versus after barrier* & NS & - & NS & NS & - \\
\hline
\end{tabular}


Table 3 Location of last known residence of people who died by jumping from Toronto bridges before (1993-2001) and after (July 2003-June 2007)*† construction of a suicide prevention barrier at Bloor Street Viaduct

No (\%) completing suicide by jumping before the barrier $(n=57)$

\begin{tabular}{|c|c|c|c|}
\hline \multirow{2}{*}{ Location of residence } & & \multirow{2}{*}{$\begin{array}{c}\text { other bridges after the } \\
\text { barrier }(n=61)\end{array}$} \\
\hline & Bloor Street Viaduct & Other bridges & \\
\hline Toronto & $17(29.8)$ & $23(40.4)$ & $41(67.2)$ \\
\hline Suburbs or beyond & $2(3.5)$ & $0(0)$ & $9(14.8)$ \\
\hline No fixed address/unknown & $4(7.0)$ & $11(19.3)$ & $11(18.0)$ \\
\hline
\end{tabular}

*Postal codes were available for this analysis only from 1999.

† More people travelled from outside the city in the period after the barrier: $X^{2}=3.8, d f=1, P=0.049$. education, combat stigma, and improve accessibility of services to people contemplating suicide. ${ }^{28}$ It is unclear whether a different result would have been observed if the barrier at Bloor Street Viaduct had been part of a more comprehensive suicide prevention programme. Furthermore, at least one prominent newspaper article published shortly after the barrier's construction speculated that it failed to prevent suicides because people were jumping at other locations. ${ }^{29}$ In September 2003, the article reported that someone who had contemplated suicide at Bloor Street Viaduct subsequently jumped from a nearby bridge on discovery of the barrier. While results of the present study would seem to agree with the article's assertion, it is possible that the article itself may have influenced people contemplating suicide to consider other bridges. Moreover, it could have contributed to a widespread public belief in the inevitability of suicide, which may have further dissuaded suicidal people from seeking help. The article and other media reports on suicide may have influenced suicide rates and could have contributed to the observation that rates of suicide by jumping did not change in the period after the barrier. Interestingly, during the study 1998 and 2002 were the years with the highest number of suicides at Bloor Street Viaduct $(\mathrm{n}=19)$; respectively, the year of the coroner's inquest into suicide at Bloor Street Viaduct and the year the barrier was constructed. This suggests that, at least in those instances, publicity may have influenced patterns of suicide by jumping in Toronto.

Whether the barrier at Bloor Street Viaduct has had an impact on factors other than rates of completed suicide is outside the scope of this research. None the less, other reasons may exist as to why people might want to prevent suicides at a particular location. Several of the charts reviewed for this study noted vehicular trauma to the bodies of the deceased. This underscores the fact that there may be social consequences to people jumping on to busy roads, including psychological or physical morbidity as well as mortality risk to bystanders as a result of motor vehicle collisions, damage to property, disruption to travel networks, and impact on the economy. By eliminating all suicides at Bloor Street Viaduct in the period after the barrier, the barrier prevented such negative social consequences. Similar negative outcomes may, however, have increased at other bridges and buildings.

\section{Strengths and limitations of the study}

The barrier at Bloor Street Viaduct is an opportunity for a fascinating natural experiment. It provides what is perhaps the best scenario for testing whether such barriers are effective because the bridge had the second highest yearly rate of suicides after Golden Gate Bridge and because, unlike other locations such as San Francisco, no bridges in Toronto span large bodies of water, meaning that essentially all suicides by jumping in Toronto come to the attention of the coroner and are recorded. Furthermore, demographic data for people who completed suicide by jumping from Bloor Street Viaduct (median age 36, 79\% male) were similar to data recently reported for people who jumped at Golden Gate Bridge (median age 40, 74\% male). ${ }^{21}$

As in any natural experiment, however, this research has many uncontrolled variables. Firstly, despite the relatively high rate of suicides by jumping at Bloor Street Viaduct, the absolute numbers may have been too low to achieve adequate power in a study of this kind. Secondly, despite the relative comprehensiveness of the chief coroner's records, it is possible that suicide rates by all causes were overestimated or underestimated in the period before or after the barrier owing to incompleteness or inaccuracy of records. Thirdly, the coroner's records might be prone to bias because people found dead beneath certain bridges or after falling from any bridge or building are more likely to have been ruled as having died by suicide than by causes such as homicide or unintentional death. Finally, it is possible that an ecological fallacy is operating. Suicide in itself is a rare event and suicides by jumping are uncommon to an even greater extent. Despite the remarkably stable number of suicides by jumping in Toronto before the barrier, the possibility that rates of suicide at other bridges increased after the barrier for reasons other than substitution of location cannot be discounted. These reasons might include chance fluctuations in rates, economic changes, social changes, or other interventions to restrict the means of completing suicide. It is conceivable that the barrier led to a reduction in suicides but that this was masked by one or more of these uncontrolled variables.

\section{Conclusions}

No suicides occurred at Bloor Street Viaduct in the four years after the construction of a barrier; however, suicide rates by jumping in Toronto were unchanged because of a statistically significant increase in suicides by jumping from other bridges and a non-significant increase in suicides by jumping from buildings. This suggests that the availability of Bloor Street Viaduct was not an essential element for people contemplating suicide by jumping in Toronto. We speculate that a different result may be observed if a bridge holds a more powerful influence on suicidal people. This may be the case for Golden Gate Bridge, for example, although further evidence is needed. A safety net might be installed at Golden Gate Bridge in the near future, ${ }^{24}$ so research similar to the present study might be possible in San Francisco. However, logistical challenges may be 


\section{WHAT IS ALREADY KNOWN ON THIS TOPIC}

Evidence shows that barriers decrease or eliminate suicides at bridges commonly used for suicide by jumping

No study has shown a statistical drop in overall rates of suicide after the construction of a barrier on a bridge

It is unclear whether barriers prevent suicides or simply result in people substituting one bridge for another or attempting suicide by other means

\section{WHAT THIS STUDY ADDS}

No suicides occurred at Bloor Street Viaduct in Toronto after the construction of a barrier

Suicide rates by jumping were unchanged owing to a corresponding increase in jumps from other bridges and buildings in the area

Therefore barriers may not decrease suicide rates when comparable locations are available

greater because the major bridges in San Francisco are over water, making it more difficult to obtain accurate counts for suicide. This research shows that constructing a barrier on a bridge with a high rate of suicide by jumping is likely to reduce or eliminate suicides at that bridge but it may not alter absolute suicide rates by jumping when there are comparable bridges nearby.

We thank James Edwards (regional supervising coroner for Toronto East) and the entire staff at the Office of the Chief Coroner of Ontario, including Dorothy Zwolakowski, June Lindsell, Tina Baker, and Karen Bridgman-Acker, for making this research possible; lan Johnson and the determinants of community health course at the University of Toronto medical school for facilitating the genesis of this project; Alex Kiss (Department of Research Design and Biostatistics, Sunnybrook Health Sciences Centre) for performing some of the statistical analyses; and Donald Redelmeier (director of the Clinical Epidemiology Unit, Sunnybrook Health Sciences Centre) and David Streiner (senior scientist, KuninLunenfeld Applied Research Unit, Baycrest) for their advice and counsel. Contributors: MS developed the idea for this study, contributed to the study design, analysed the data, interpreted the results, and drafted the manuscript. He is guarantor. AlL contributed to the study design, interpreted the results, and critically revised the manuscript. Both authors had full access to all of the data (including statistical reports and tables) in the study and can take responsibility for the integrity of the data and the accuracy of the data analysis.

Funding: This study received no funding.

Competing interests: All authors have completed the unified competing interest form at www.icmje.org/coi_disclosure.pdf (available on request from the corresponding author) and declare (1) no financial support for the submitted work from anyone other than their employer; (2) AJL has acted as a consultant for Janssen Ortho, Biovail, and Eli Lilly Canada; (3) no spouses, partners, or children with relationships with commercial entities that might have an interest in the submitted work; and (4) no nonfinancial interests that may be relevant to the submitted work. Ethical approval: This study was approved by the University of Toronto's research ethics board.

Data sharing: No additional data available.

1 Gunnell D, Middleton N, Frankel S. Method availability and the prevention of suicide: a re-analysis of secular trends in England and Wales 1950-1975. Soc Psychiatry Psychiatr Epidemiol 2000;35:437-43.

2 Kreitman N. The coal gas story: United Kingdom suicide rates, 1960 1971. BrJ Prev Soc Med 1976;30:86-93.

3 Hawton K, Simkin S, Deeks J, Cooper J, Johnston A, Waters K, et al. UK legislation on analgesic packs: before and after study of long term effect on poisonings. BMJ 2004;329:1076-9.

4 Hawton K, Townsend E, Deeks J, Appleby L, Gunnell D, Bennewith O, et al. Effects of legislation restricting pack sizes of paracetamol and salicylate on self poisoning in the UK: before and after study. $B M$ / 2001;322:1203-7.

5 Amos T, Appleby L, Kiernan K. Changes in rates of suicide by car exhaust asphyxiation in England and Wales. Psychol Med 2001;31:935-9.

6 Beautrais AL, Fergusson DM, Horwood LJ. Firearms legislation and reductions in firearm-related suicide deaths in New Zealand. Aust NZ J Psychiatry 2006;40:253-9.

7 Leenaars AA, Moksony F, Lester D, Wenckstern S. The impact of gun control (Bill C-51) on suicide in Canada. Death Stud 2003;27:103-24.

8 Sloan JH, Rivara FP, Reay DT, Ferris JA, Kellermann AL. Firearm regulations and rates of suicide. A comparison of two metropolitan areas. N Engl I Med 1990;322:369-73.

9 Rich CL, Young JG, Fowler RC, Wagner J, Black NA. Guns and suicide: possible effects of some specific legislation. Am J Psychiatry 1990;147:342-6.

10 Gunnell D, Nowers M. Suicide by jumping. Acta Psychiatr Scand 1997;96:1-6.

11 Zarkowski P. The aurora bridge. Am J Psychiatry 2008;165:1126

12 Rosen DH. Suicide survivors. A follow-up study of persons who survived jumping from the Golden Gate and San Francisco-Oakland Bay Bridges. West J Med 1975;122:289-94.

13 Seiden RH. Where are they now? A follow-up study of suicide attempters from the Golden Gate Bridge. Suicide Life Threat Behav 1978;8:203-16

14 Miller M, Azrael D, Hemenway D. Belief in the inevitability of suicide: results from a national survey. Suicide Life Threat Behav 2006;36:1-11.

15 Pelletier AR. Preventing suicide by jumping: the effect of a bridge safety fence. Inj Prev 2007;13:57-9.

16 Bennewith O, Nowers M, Gunnell D. Effect of barriers on the Clifton suspension bridge, England, on local patterns of suicide: implications for prevention. Br J Psychiatry 2007;190:266-7.

17 Reisch T, Michel K. Securing a suicide hot spot: effects of a safety net at the Bern Muenster Terrace. Suicide Life Threat Behav 2005;35:460-7

18 Glenn WM. The magnet and the veil. MD Canada 2003;May/Jun:36-42.

19 University of Waterloo. Bloor Street Viaduct suicide barrier designed. 2001. http://newsrelease.uwaterloo.ca/archive/news.php? id $=2379$.

20 University of Waterloo. The luminous veil Prince Edward Viaduct safety barriers. 2005. www.architecture.uwaterloo.ca/ faculty_projects/terri/steel/veil.html.

21 Statistics Canada. Population and dwelling counts for Toronto and Ontario. 2010. www12.statcan.ca/census-recensement/2006/dp$\mathrm{pd} / \mathrm{prof} / 92-591 /$ details/page.cfm? Lang=E\&Geo1=CSD\&Code1 $=3520005 \&$ Geo2 $=$ PR \&Code $2=35 \&$ Da$=\mathrm{E} \& \mathrm{Geo} 1=\mathrm{CSD} \&$ Code $1=3520005 \& \mathrm{Geo} 2=\mathrm{PR} \&$ Code $2=35 \& \mathrm{Data}=-$ $=$ CSD $\&$ Code $1=3520005 \&$ Geo $2=P R \&$ Code $2=35 \&$ Data $=$ Count $\&$ $=3520005 \& G e 02=P R \& C o d e 2=35 \& D a t a=$ Count $\&$ SearchText=toron $=$ PR\&Code2=35\&Data=Count\&SearchText=toronto\&SearchType=$=35 \&$ Data $=$ Count $\&$ SearchText=toronto $\&$ SearchType $=$ Begins $\&-$ SearchPR $=01 \& B 1=A l l \&$ Custom $=$ and www12.statcan.ca/english/ Profil01/CP01/Details/Page.cfm? Lang $=$ E \&Geo1 $=$ CSD $\&$ Code $1=3520005 \&$ Geo2 $=P R \& C o d e 2=35 \&$ Da$=E \& G e 01=C S D \& C o d e 1=3520005 \& G e 02=P R \& C o d e 2=35 \& D a t a=$ $=$ CSD $\&$ Code $1=3520005 \&$ Geo $2=P R \&$ Code $2=35 \&$ Data $=$ Count $\&$. $=3520005 \&$ Geo $2=P R \&$ Code2 $=35 \&$ Data $=$ Count $\&$ SearchText=toron $=$ PR\&Code $2=35 \&$ Data $=$ Count $\&$ SearchText=toronto $\&$ SearchType $=-$ $=35 \&$ Data $=$ Count $\&$ SearchText=toronto $\&$ SearchType=Begins $\&$ SearchPR=01\&B1=All\&Custom $=$.

22 Beautrais AL. Effectiveness of barriers at suicide jumping sites: a case study. Aust NZ J Psychiatry 2001;35:557-62.

23 Beautrais AL, Gibb SJ, Fergusson DM, Horwood LJ, Larkin GL. Removing bridge barriers stimulates suicides: an unfortunate natura experiment. Aust NZ J Psychiatry 2009;43:495-7.

24 Blaustein M, Fleming A. Suicide from the Golden Gate Bridge. Am J Psychiatry 2009;166:1111-6.

25 Barenaked Ladies. War on drugs. Reprise Records, 2003.

26 Ondaatje M. In the skin of a lion. Vintage Canada, 1996.

27 Cantor CH, Hill MA. Suicide from river bridges. Aust NZ J Psychiatry 1990;24:377-80.

28 Cole-King A, Lepping P. Suicide mitigation: time for a more realistic approach. BrJ Gen Pract 2010;60:1-3.

29 Harding K. The new suicide bridge. The Globe and Mail, 6 Sep;2003.

Accepted: 27 April 2010 